\title{
Reticular synthesis and the design of new materials
}

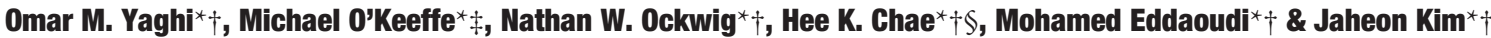

${ }^{*}$ Materials Design and Discovery Group, †Department of Chemistry, 930 N. University Avenue, University of Michigan, Ann Arbor, Michigan 48109-1055, USA $\ddagger$ Department of Chemistry, Arizona State University, Tempe, Arizona 85287-1604, USA

$\$$ Permanent address: Hankuk University of Foreign Studies, Korea

The long-standing challenge of designing and constructing new crystalline solid-state materials from molecular building blocks is just beginning to be addressed with success. A conceptual approach that requires the use of secondary building units to direct the assembly of ordered frameworks epitomizes this process: we call this approach reticular synthesis. This chemistry has yielded materials designed to have predetermined structures, compositions and properties. In particular, highly porous frameworks held together by strong metal-oxygen-carbon bonds and with exceptionally large surface area and capacity for gas storage have been prepared and their pore metrics systematically varied and functionalized.

lthough the synthesis of new materials has long been recognized as the most essential element in advancing technology, it generally remains more of an art than a science-in that the discovery of new compounds has mostly been serendipitous, using methods referred to by critics as 'shake and bake', 'mix and wait' and 'heat and beat'. For much of the twentieth century, this worked well for the synthesis of important solid-state materials, and we expect that it will continue to yield interesting compounds. However, it is becoming increasingly urgent to produce materials designed to perform highly specific and cooperative functions $s^{1,2}$.

Recent extensive research into the design and synthesis of metalorganic frameworks (MOFs) has led to numerous practical and conceptual developments in that direction ${ }^{3-7}$. Specifically, the chemistry of MOFs has provided an extensive class of crystalline materials with high stability, tunable metrics, organic functionality, and porosity. Here we present some of the important developments that have shaped this rapidly growing field and propose a general conceptual framework, which serves as a useful tool in designing materials constructed from molecular building blocks.

\section{Reticular synthesis}

General lack of control over the character of solids produced from the traditional synthetic methods is directly related to the fact that the starting entities do not maintain their structure during the reaction, leading to poor correlation between reactants and products. We have shown that the design of an extended network can be realized by starting with well-defined and rigid molecular building blocks that will maintain their structural integrity throughout the construction process ${ }^{3,8}$. Alternatively, the use of well-defined conditions that lead to the formation of such building blocks in situ is an equally viable approach to the design of extended structures and one that has been especially fruitful in MOF chemistry $^{8}$. We have shown ${ }^{8,9}$ that the practice of logical synthesis must begin with knowledge of the target network 'blueprint' and identification of the required building blocks for its assembly. This process is central to our ability to achieve true design of solid-state materials: we refer to its implementation as reticular synthesis.

In essence, reticular synthesis can be described as the process of assembling judiciously designed rigid molecular building blocks into predetermined ordered structures (networks), which are held together by strong bonding. It is different from retrosynthesis of organic compounds ${ }^{10}$, because the structural integrity and rigidity of the building blocks in reticular synthesis remain unaltered throughout the construction process-an important aspect that could help to realize fully the benefits of design in crystalline solid-state frameworks. Similarly, reticular synthesis should be distinguished from supramolecular assembly ${ }^{11}$, because in the former, building blocks are linked by strong bonds throughout the crystal.

In this context, it is worth noting that a plethora of extended structures successfully prepared by copolymerization of metal ions with organic links have been reported and reviewed under the rubric of 'crystal engineering', a term which has mutated somewhat over the years and which is now rather broadly defined ${ }^{12-14}$. We use the more precise term reticular synthesis (or chemistry) to describe the logical approach to the synthesis of robust materials with predesigned building blocks, extended structures, and properties. Thus, it might be considered a subclass of crystal engineering.

Research in the area of MOFs and, to a lesser extent, inorganic frameworks, has recently progressed far enough to provide examples which show the feasibility of the building-block approach and the scope of reticular synthesis. Here we take selected examples to highlight the ideas involved, with emphasis on our own work on MOFs in which structural and thermal stability characterization have been combined with in-depth studies of surface area and gas sorption capacities. The subject of metal-organic frameworks has a long history, however, so we begin by giving some perspectives on the field.

\section{Perspectives and challenges}

The Cambridge Structure Database (CSD) documents the crystal structures of more than 11,000 extended metal-organic compounds in which a metal ion or cluster has been linked by an organic moiety in which the linking functionality is a cyanide, pyridyl, phosphate or carboxylate. Of these, nearly 3,000 compounds have threedimensional (3D) structures and about double that number have 2D structures. MOFs composed of the first-row transition metals and organic links such as cyanide ${ }^{15,16}$, glutamate ${ }^{17}$, formate ${ }^{18}$, triazole $^{19}$, oxalate ${ }^{20}, 1,2,4,5$-tetracarboxylates ${ }^{21}$ and squarates ${ }^{22}$ have long been known. Also, expanded diamond structures based on linking of $\mathrm{Cu}(\mathrm{I})$ with $\mathrm{ANT}^{23}, \mathrm{DCNQ}^{24}$ and $\mathrm{TCTPM}^{25}$, and decorated diamond structures based on linking $\mathrm{Mn}$ (II) with $\mathrm{Ge}_{4} \mathrm{~S}_{10}^{4-}$ (T2) clusters ${ }^{9}$ (see Box 1 for abbreviations of chemical names and clarification of terms) represent the numerous forerunners of the extended structures constructed from molecular building blocks. Subsequently, other compounds based on linking metal ions with $\mathrm{ADC}^{26}, \mathrm{ETC}^{27}, \mathrm{INT}^{28}$, $\mathrm{BPY}^{29,30}$ and $\mathrm{BPCN}^{31}$ have been reported. Tetrahedral building blocks such as $\mathrm{HMT}^{32}$ and 
$\mathrm{MCP}^{33}$ have been linked by metal ions to form decorated diamond structures, while $\mathrm{TPY}^{34}$ and $\mathrm{ATC}^{35}$ are examples of links predesigned so that their assembly into diamond networks is done by linking through hydrogen bonding.
Consideration of this range of crystal structures, in particular those of MOFs, has led us to identify two critical questions for reticular synthesis. First, of the almost unlimited possible networks, which can be expected to form and how can they be synthesized?

Box 1

Definitions and structures

Here we define some terms and illustrate organic species referred to in the text by abbreviations in the Box 1 figure.

Reticular: (adjective) having the form of a (usually periodic) net. Isoreticular: Based on the same net (having the same topology). MOF-n: Metal-organic framework (with $n$ an integer assigned in roughly chronological order).

IRMOF-n: Isoreticular MOF (with $n$ an integer referring to a member of the series).

Interpenetration: A term used to describe the mutual intergrowth of two or more networks in a structure where the networks are physically but not chemically linked. See refs 4 and 8 for reviews on this property.

Expansion: Increasing the spacing between vertices in a network. Decoration: Replacing a vertex in a net by a group of vertices. SBU: The term 'secondary building unit' has been used for some time to describe conceptual fragments of zeolites; in the context of reticular chemistry it refers to the geometry of the units defined by the points of extension (such as the carboxylate $\mathrm{C}$ atoms in most carboxylate MOFs).

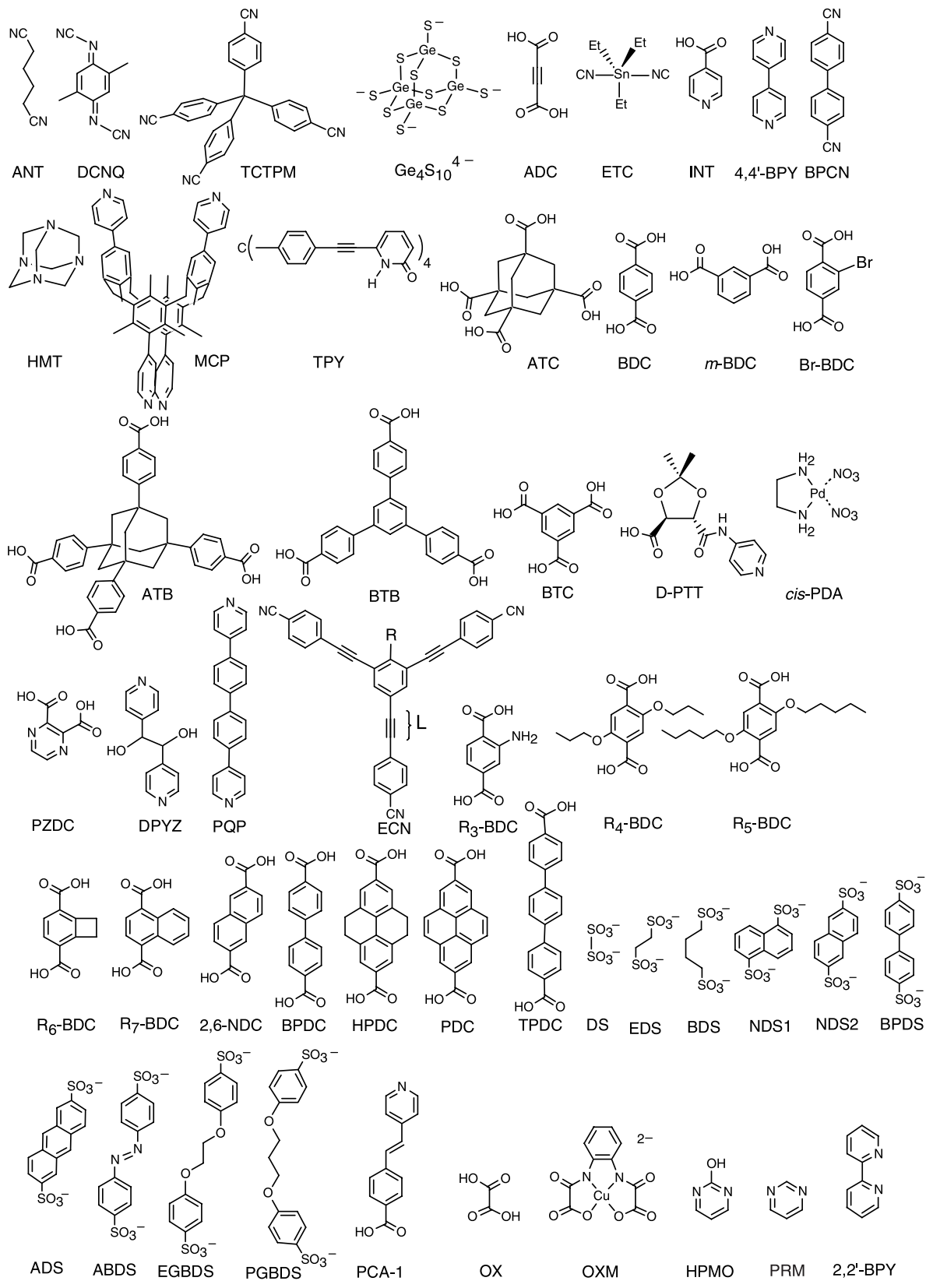


Second, with few exceptions, MOFs based on M-N linkages in which the vertex of the network is just a single atom have a tendency to form structures which collapse upon removal of 'guest' atoms from the pores, rendering the structure nonporous. How then can we ensure that our structures will be robust?

\section{Secondary building units}

To address these questions it is important to first appreciate that it is difficult (although not impossible) to attempt a priori synthesis of structures, such as those presented above, from simple metal ions and organic links because ions hold little directional information. This relative lack of directionality often results in flexibility around the metal ion, a multiplicity of possible structures and a general lack of control-as exemplified by frameworks based on $\mathrm{Cu}$ ions and bipyridine and related links ${ }^{13,36-42}$. We have focused on using the carboxylate functionality to chelate metal ions and lock them into rigid and thus directional metal-oxygen-carbon clusters, with the

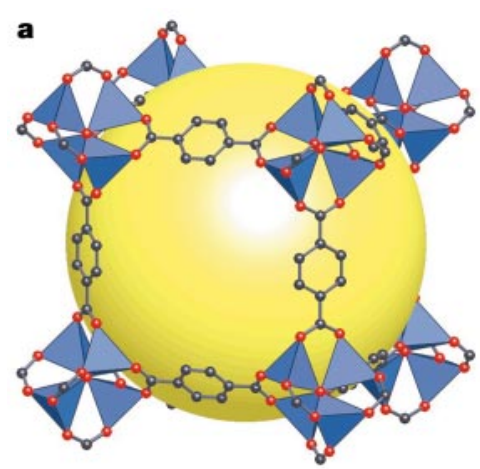

b
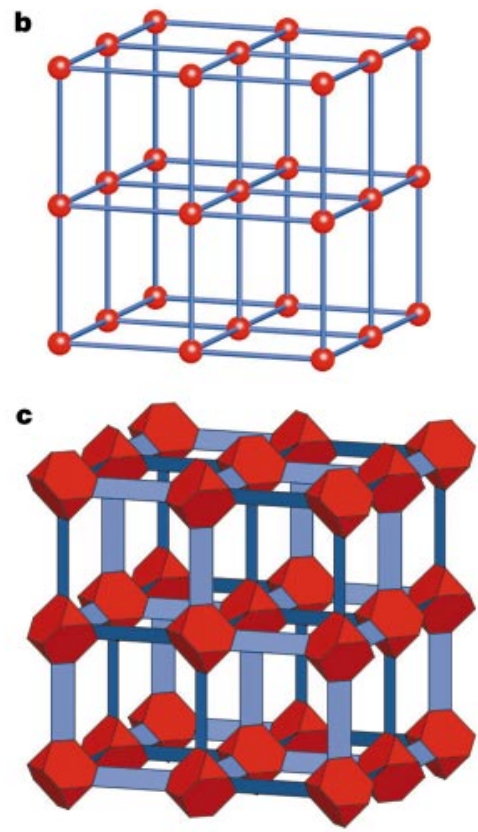

Figure 1 The MOF-5 structure and its topology. a, The MOF-5 structure shown as $\mathrm{ZnO}_{4}$ tetrahedra (blue polyhedra) joined by benzene dicarboxylate linkers $(0$, red and $\mathrm{C}$, black) to give an extended 3D cubic framework with interconnected pores of $8 \AA$ aperture width and $12 \AA$ pore (yellow sphere) diameter. (Yellow sphere represents the largest sphere that can occupy the pores without coming within the van der Waals size of the framework). $\mathbf{b}$, The topology of the structure (primitive cubic net) shown as a balland-stick model. c, The structure shown as the envelopes of the $\left(0 \mathrm{Zn}_{4}\right) \mathrm{O}_{12}$ cluster (red truncated tetrahedron) and benzene dicarboxylate (BDC) ion (blue slat). Note that opposing slats are all at $90^{\circ}$. points of extension (in this example, carboxylate $\mathrm{C}$ atoms) defining geometrical shapes referred to as secondary building units (SBUs) ${ }^{26}$. The successful design of rigid frameworks based on such SBUs was demonstrated for the first time in MOF-2 (see ref. 43 and below) and MOF- $5^{44}$. The design principles employed for MOF- 5 will be discussed here to show that SBUs have intrinsic geometric properties that facilitate network design and help us to address the issues of network synthesis and robustness.

In MOF-5 (Fig. 1a), $\mathrm{Zn}_{4} \mathrm{O}\left(\mathrm{CO}_{2}\right)_{6}$ units containing four $\mathrm{ZnO}_{4}$ tetrahedra with a common vertex and six carboxylate $\mathrm{C}$ atoms that define an octahedral SBU are joined together by benzene links. This leads to a cubic network in which the vertices are the octahedral SBUs and the edges are the benzene struts. In practice, this compound was prepared from $\mathrm{Zn}$ (II) and BDC acid under conditions pre-determined to yield the octahedral SBU in situ. Because the SBU and benzene links are relatively large and rigid entities, the structure produced has exceptional porosity (indicated by its sorption), and stability (indicated by thermal analysis and single crystal $\mathrm{X}$-ray diffraction studies on the completely evacuated framework $\left.^{8,44}\right)$.

The exceptional stability of MOF-5 can be understood by comparing its basic network, composed of single atom vertices (Fig. 1b), with the actual structure of MOF-5, which has cationic clusters at those vertices (Fig. 1a). The basic network has no resistance to shear if the links are considered to be universal joints. However, in the actual MOF-5 structure, the cationic clusters have a truncated tetrahedral envelope (Fig. 1c), and the rigidly planar $\mathrm{O}_{2} \mathrm{C}-\mathrm{C}_{6} \mathrm{H}_{4}-\mathrm{CO}_{2}$ linkers have a planar slat envelope. The linkage of these two groups produces an inherently rigid structure held together by mutually perpendicular hinges.

This approach, based on the concept of SBUs, has been useful in rationalizing the topologies of MOF structures ${ }^{26}$, and more importantly, it has allowed the synthesis and use of a large number of inorganic and organic SBUs with varying geometries (Fig. 2) 26,43-52. In many of these cases, identifying the reaction conditions that produce an SBU with a specific geometry in situ means that the addition of a rigid organic SBU will result in the formation of a predetermined network. In other words, with this strategy it is now possible to control the overall coordination number of the inorganic and organic SBUs, and therefore the need to identify the networks that are expected to form from different geometric shapes becomes particularly acute.

\section{Possible framework topologies}

Which framework topology can be expected to form is of critical importance because there are a large number of possible structures for each geometrical shape. For example, more than 100 different topologies (in addition to that of diamond) ${ }^{53}$ are possible for linking tetrahedral building blocks together into structures with just one kind of vertex (that is, all vertices related by symmetry), and the would-be designer must find some criteria for deciding which will be selected.

We have recently argued that in general only a small number of simple, high-symmetry structures will be of overriding general importance, and they would be expected to form most commonly ${ }^{54}$. We call these default structures, in that they would be expected to form if the assembly reaction involved simple building blocks, especially single atoms (ions) joined by flexible linkers. More complicated structures can be targeted by judicious use of appropriately shaped SBUs and linkers (we give examples below). A list of some default structures ${ }^{54}$ and some criteria for their classification $^{55-60}$ are given in Box 2.

We have undertaken a systematic survey ${ }^{59}$ of structures with the goal of design in mind. There are just six three-periodic structures with one kind of vertex, edge and ring-we call these regular and quasi-regular. The next most regular are those with just one kind of link. Their enumeration is mostly straightforward and-together 
with the regular structures-they are the most common structures used in reticular chemistry, because one almost always attempts a synthesis with just one kind of linker. As an illustration, we $e^{48}$ have enumerated the nine principal ways in which square SBUs can be joined by equal linkers to form polyhedra, rods, layers or threedimensional nets. In the next section we show how this enumeration allows particular linked-square structures of each different dimensionality to be successfully targeted for synthesis using appropriately shaped linkers.

\section{Design and synthesis of pre-determined frameworks}

As we noted above, metal-containing (cationic) SBUs are not isolatable entities, and so it has been essential to establish the exact chemical conditions that will yield a specific SBU in situ. On the other hand, organic (anionic) SBUs are pre-assembled using the considerable sophistication of organic synthetic methods ${ }^{10}$-see Box 1 and Fig. 2 for examples. For a given cationic SBU the geometry of the organic unit plays an important role in directing the structure. This is illustrated (Fig. 3) for four structures ${ }^{41,61-63}$ of different dimensionality (periodicity-0-D refers to an object within only point symmetries): a truncated cuboctahedron (0D), a linear rod (1D) the square grid (2D), and the $\mathrm{NbO}$ network (3D) based on linkage of paddle-wheel clusters by ditopic linkers. The dihedral angle between the paddle wheels (square SBUs) plays a crucial role in determining which one of these structures will be produced. The reaction conditions that would yield the paddle-wheel clusters were used in the presence of the appropriate link, to give the desired structure-which is in each case the only possible structure given identical linkers of the shape indicated.

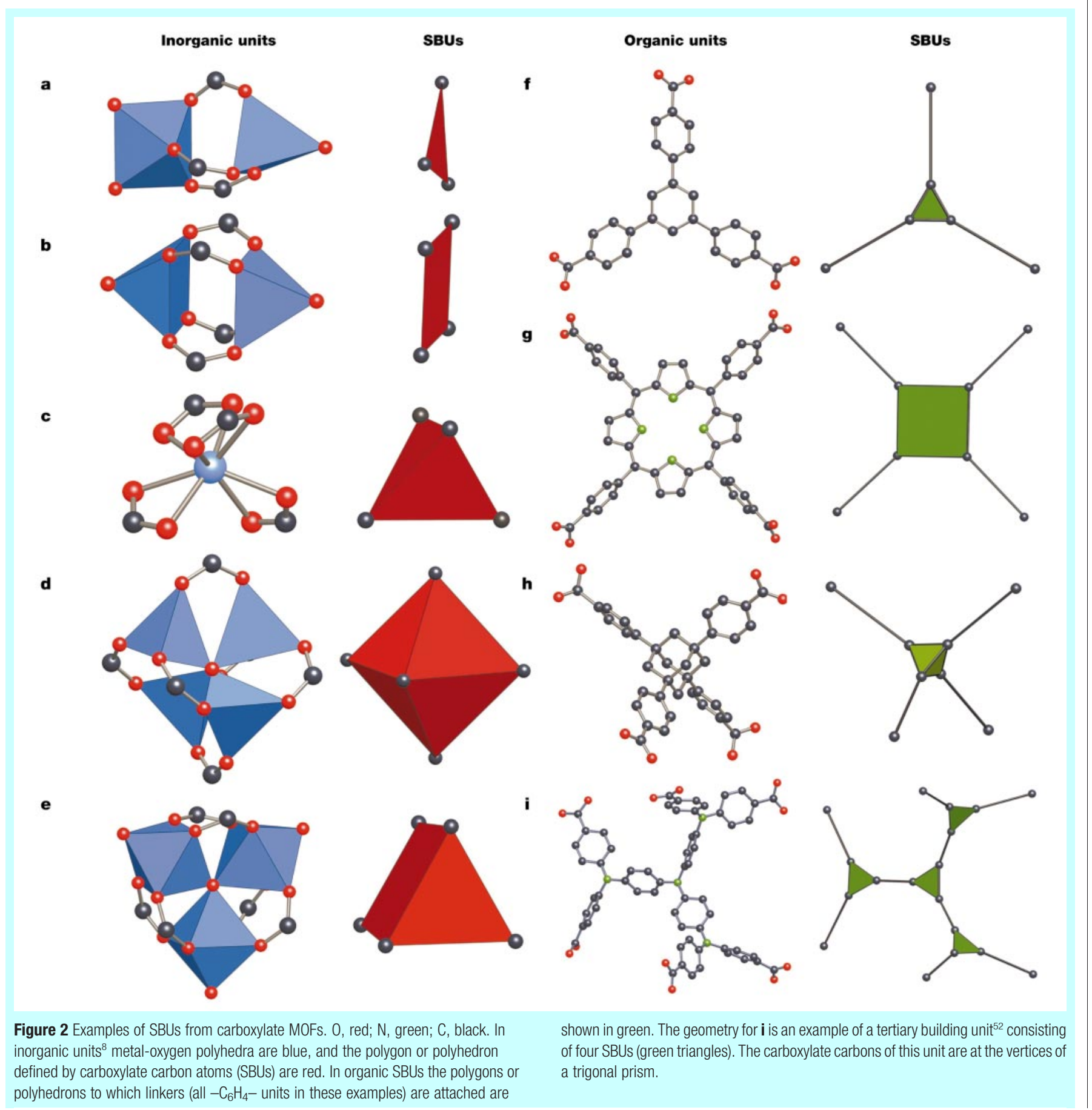


This approach can be used in linking together other SBU shapes. For example, the PtS net is the default structure for linking squares $(\mathrm{Pt})$ and tetrahedra $(\mathrm{S})$. Assembly of the paddle wheel with ATC and ATB (tetrahedral SBUs) yields MOF- $11^{51}$ and MOF- $36^{26}$, which are indeed based on the PtS net. There are only two ways of linking square and triangular SBUs-these are the nets named for $\mathrm{Pt}_{3} \mathrm{O}_{4}$ and 'twisted boracite'-and they might both be considered default structures $^{54}$ (Box 2). Again, linking a copper-based paddle wheel with triangular SBUs, either BTB or BTC, gives MOF- $14^{49}$ with the $\mathrm{Pt}_{3} \mathrm{O}_{4}$ topology and HKUST- $1^{64}$ with the twisted boracite topology, respectively. Examination of the parent nets shows that the simpler $\mathrm{Pt}_{3} \mathrm{O}_{4}$ net requires the more flexible BTB links.

The regular (and hence default) structure for linking triangles is the chiral 3D Si network in $\mathrm{SrSi}_{2}$, which has been a target of reticular synthesis $^{45,65}$. Interestingly, it is composed of achiral triangular vertices, which twist with respect to adjacent like vertices by a dihedral angle of $70.5^{\circ}$ to make an overall chiral arrangement. This topology was assembled from BTC and $\mathrm{Zn}$ (II) under conditions that give a propeller-shaped binuclear $\mathrm{M}_{2}\left(\mathrm{CO}_{2}\right)_{3} \mathrm{SBU}$ (Fig. 2a) ${ }^{45}$. Here, three carboxylate $\mathrm{C}$ atoms of the SBU are twisted with respect to the $\mathrm{C}$ atoms on the benzene ring to give chiral crystals although the bulk material is racemic. Recently, it has been demonstrated that an enantiopure MOF can be prepared from a derivative $D$-tartaric acid (D-PTT) and $\mathrm{Zn}$ (II) to give a triangular SBU, which formed a hexagonal layered network ${ }^{66}$ that was functionalized with pyridine units to allow the pores to be used for chiral catalysis.

It is worth noting that exquisite control over the outcome of reticular synthesis has also been developed using site-blocked metal complexes that express angular information. For example, cis-PDA provides $90^{\circ}$ binding angles such that with linear ditopic organic links such as $\mathrm{BPY}^{67}$, the nitrate ligands are displaced by BPY, leading to molecular squares. On the basis of this approach other metal complexes of various binding angles and a variety of branching and bent organic links have been used in the design of other polygons, platonic and archimedean polyhedra ${ }^{61,68-71}$.

Box 2

\section{Framework topologies}

The topology underlying periodic structures is that of a periodic net. Crystal chemists, particularly Wells ${ }^{15}$, have laboured to enumerate, describe and classify such nets. We ${ }^{58}$ find the approach based on tiling to be particularly fruitful ${ }^{55,56}$. The tiles are generalized polyhedra (cages) which generate the entire structure when packed together. For each periodic net there is a unique 'natural' tiling ${ }^{58}$; examples are shown in Fig. 5. The adamantane unit with ten vertices is the natural tile of the diamond net. Its four faces are six-membered rings, which we symbolize as $\left[6^{4}\right]$. The natural tiling of the lonsdaleite net has equal numbers of two tiles that are $\left[6^{3}\right]$ and $\left[6^{5}\right]$ (Fig. 5).

To classify nets we make use of the transitivity of the structure ${ }^{57}$. If there are $p$ kinds of vertex, $q$ kinds of edge (link), $r$ kinds of ring (faces of tiles) and $s$ kinds of tile, the transitivity is pqrs. It turns out ${ }^{58}$ that the five structures whose natural tilings have transitivity 1111 have coordination figures that are regular polygons or polyhedra and we call them 'regular' (see Table 1). Their importance in reticular synthesis is comparable to that of the five platonic solids in other areas of chemistry. Structures 1112 are called 'quasiregular' and structures 11 rs are 'semiregular'. These are the structures that are most likely to form with one kind of SBU joined by one kind of link. They can be enumerated fairly easily and there are only about twenty of them (the exact number depends on some subtle details of what we consider to be allowable structures). There are another twenty or so structures with two vertices and one edge. Structures with just one kind of edge (edge transitive) are the most reasonable targets of designed reticular synthesis, and thus the most important from that point of view. Even these approximately 50 structures can quickly be reduced to a smaller number. For example, there are seven edgetransitive nets with tetrahedral vertices (examples are given in Table 1) but the diamond net is the most regular, and thus the default net for tetrahedral coordination.

Of course less regular nets can be forced by low-symmetry SBUs. For example, 5-coordinated SBUs cannot be linked by just one kind (that is, symmetry equivalent) of link. Two simple examples are given in Table 1 . There is only one 3-coordinated 3D net with symmetry that requires the coordination figure to be an equilateral triangle (that of $\mathrm{SrSi}_{2}$-see Table 1). The use of 3-coordinated SBUs with a T or Y shape can accordingly lead to a lower-symmetry net such as that of $\mathrm{Si}$ in $\mathrm{ThSi}_{2}$ (also listed). The formation of the rutile net instead of the more symmetrical pyrite net in $(6,3)$-coordinated structures is often ascribable to similar causes.

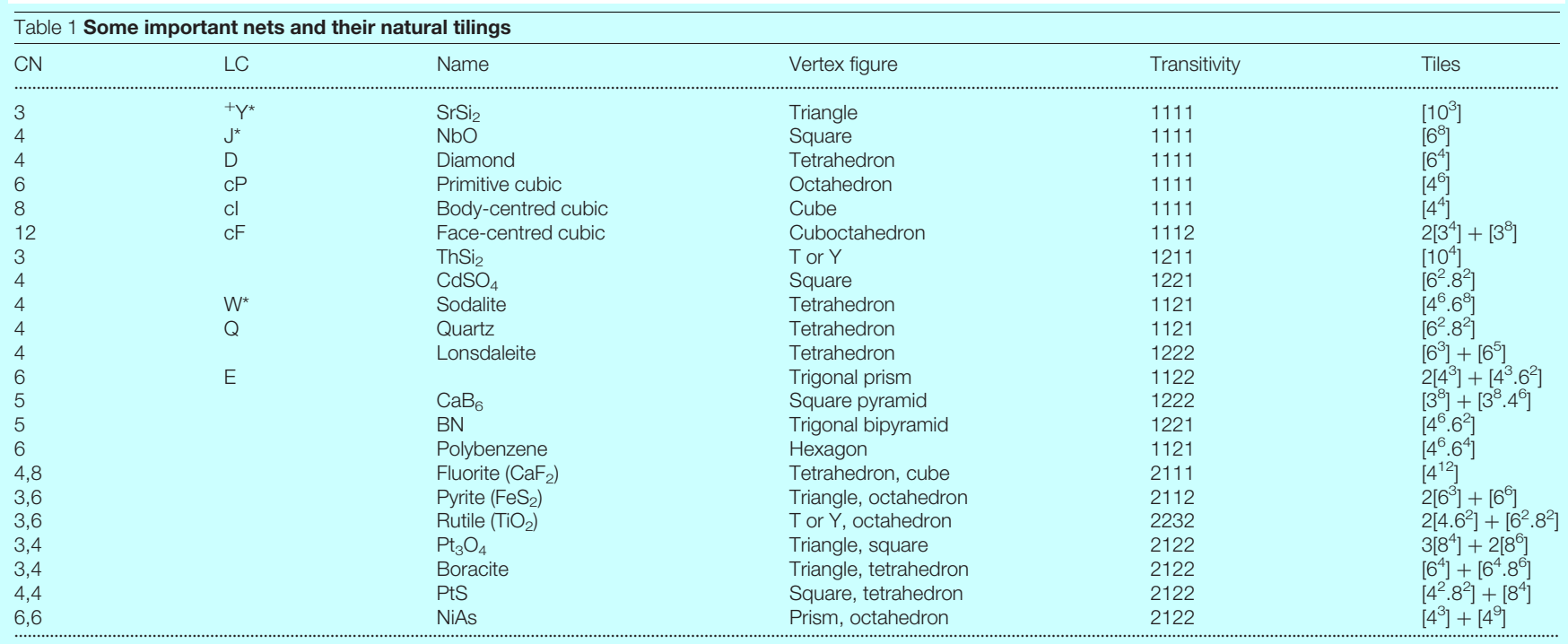

$\mathrm{CN}$ is the coordination number of the vertices. LC refers to the symbol for invariant lattice complexes ${ }^{59}$. The transitivity is defined in the text, and the entries under 'tiles' are the face symbols of the tiles. The first six rows are the five regular and one quasi-regular tilings. For illustrations of these nets see refs 54 and 60. 


\section{A new class of porous materials}

We have just argued that the rigidity and directionality of SBUs provide a means for the logical synthesis of a wide variety of frameworks. An important aspect of this approach is that the large sizes of SBUs inevitably lead to there being spaces within these structures where solvent and/or counter-ion guests reside. In many cases, such solids are interchangeably referred to as "porous" and "open-framework", without definitive proof of porosity ${ }^{72}$. We prefer to categorize them according to the mobility of the species occupying their cavities. It is inaccurate to use the term 'open framework' to refer to any low-density or large-scale structure, because 'open' implies allowing passage. We note that in many cases this property is absent (or at least undetermined in the structure in question) because passage is hindered by solvent molecules that form strong interactions with the framework; as a result, such solvent molecules are necessary to maintain the crystal architecture.

Thus we consider that 'porous' implies having pores, and pores are, in the Oxford English Dictionary definition, a "minute... opening... through which fluids or gases can pass". In addition, demonstration of porosity through gas sorption isotherms is necessary to prove permanent porosity. Indeed, we find that MOFs having structures based on inorganic SBUs are exceptionally porous with pore diameters and volumes which exceed those of the most porous and useful zeolites as shown in Fig. $4^{73-84}$.

Two important attributes of porous MOFs account for their structural stability and high porosity. First, they are essentially scaffoldings with all or most atoms on internal surfaces, which lead to the highest known surface areas $\left(2,900 \mathrm{~m}^{2} \mathrm{~g}^{-1}\right)$ and pore volumes $\left(1-2 \mathrm{~cm}^{3} \mathrm{~g}^{-1}\right)$. In other porous solids such as zeolites and molecular sieves the interior of the pores is largely composed of walls leading to relatively lower specific capacity for sorption.

Second, in contrast to frameworks of the metal bipyridine type, which are known to collapse upon removal of guests, MOFs constructed with oxide SBUs are far more robust, owing to the

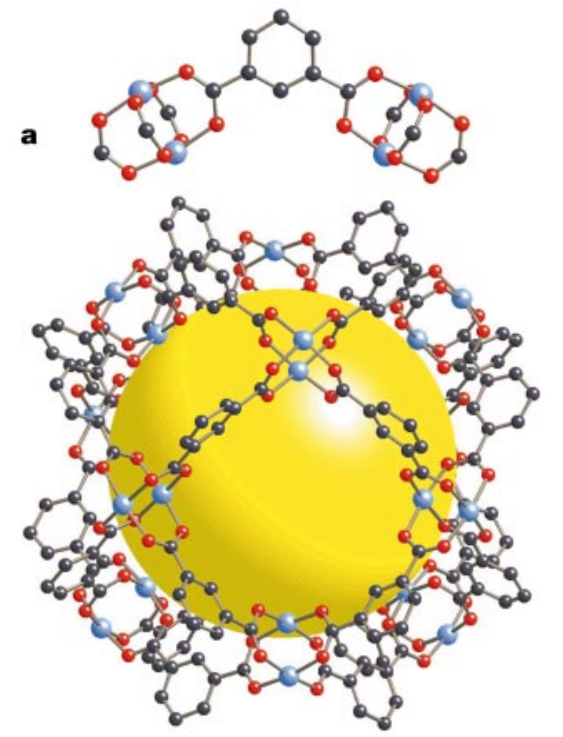

b

c
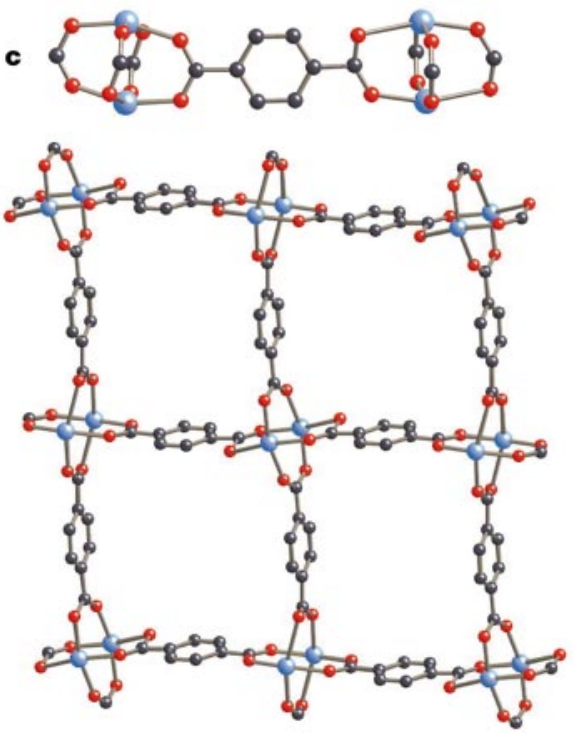

Figure 3 The control of dimensionality of linked paddle-wheel units by use of precise linker geometry. Shown are fragments of the assembled structures of MOP- $1^{61}(\mathbf{a})$, MOF-222 (Chae, H.K., Rowsell, J.R., O'Keeffe, M., Yaghi, O.M., to be published) (b),
MOF-2 ${ }^{42}$ (c) and MOF-10163 (d). C, black; O, red; Br, green; metal, blue. Above each structure, one linker is shown joined to two paddle-wheel units. The yellow spheres are at the centres of large cavities in the structures of MOP-1 and MOF-101. 
presence of strong metal-oxygen bonds. For example, in MOF-5 each link to an octahedral SBU involves two $\mathrm{Zn}-\mathrm{O}$ bonds with energy of $360 \mathrm{~kJ} \mathrm{~mol}^{-1}$ per pair (based on the heat of formation of $\mathrm{ZnO})^{85}$ comparable to the $\mathrm{C}-\mathrm{C}$ bond energy of $358 \mathrm{~kJ} \mathrm{~mol}^{-1}$ in diamond. The corresponding energy for two $\mathrm{Cu}-\mathrm{O}$ bonds (as in linked paddle wheels) is $372 \mathrm{~kJ} \mathrm{~mol}^{-1}$. In contrast, we estimate from the heats of formation of ammoniates such as $\mathrm{CuCl} \cdot 3 \mathrm{NH}_{3}$ and $\mathrm{CuCl}_{2} \cdot 2 \mathrm{NH}_{3}$ that the energy of the $\mathrm{Cu}(\mathrm{I})-\mathrm{N}$ coordination bond is about $55 \mathrm{~kJ} \mathrm{~mol}^{-1}$ and the $\mathrm{Cu}(\mathrm{II})-\mathrm{N}$ bond is about $90 \mathrm{~kJ} \mathrm{~mol}^{-1}$ : very much weaker, and indeed the weak link in metal-bipyridine type frameworks.

\section{Frameworks with adjustable metrics and properties}

An important step forward has been the use of expanded links such as ECN which can be linked into MOF structures in which the pores can be functionalized by modifying $\mathrm{R}^{86}$, and expanded by lengthening $\mathrm{L}$ (see Box 1). When assembled with $\mathrm{Ag}(\mathrm{I})$ this link gives networks based on the Si network in $\mathrm{ThSi}_{2}$ (Box 2). It is interesting to note that the unfunctionalized $(\mathrm{R}=\mathrm{H})$ link also gives the same network. This finding indicates that the presence of functional groups $(\mathrm{R})$ does not alter the course of reticulation. In other words, all frameworks produced by this method are isoreticular (having the same network topology). These compounds have not been shown to have permanent porosity or rigid frameworks, which is not surprising as they are not based on vertices of clusters (SBUs), but rather on single Ag ion vertices, which do not provide for the prerequisite rigidity.

On the other hand, frameworks isoreticular with MOF-5 have been synthesized with functionalized structures and shown to have permanent porosity. Employing each of the links: $o-\mathrm{Br}-\mathrm{BDC}, \mathrm{R}_{3}-$ BDC, $\mathrm{R}_{4}$-BDC, $\mathrm{R}_{5}$-BDC, $\mathrm{R}_{6}$-BDC, $\mathrm{R}_{7}$-BDC, 2,6-NDC, BPDC, HPDC, PDC and TPDC instead of BDC yielded IRMOF-2 to IRMOF-16, including the non-interpenetrating structures of BPDC, HPDC, PDC and TPDC. Each member of the IRMOF series has been isolated and characterized by single-crystal X-ray

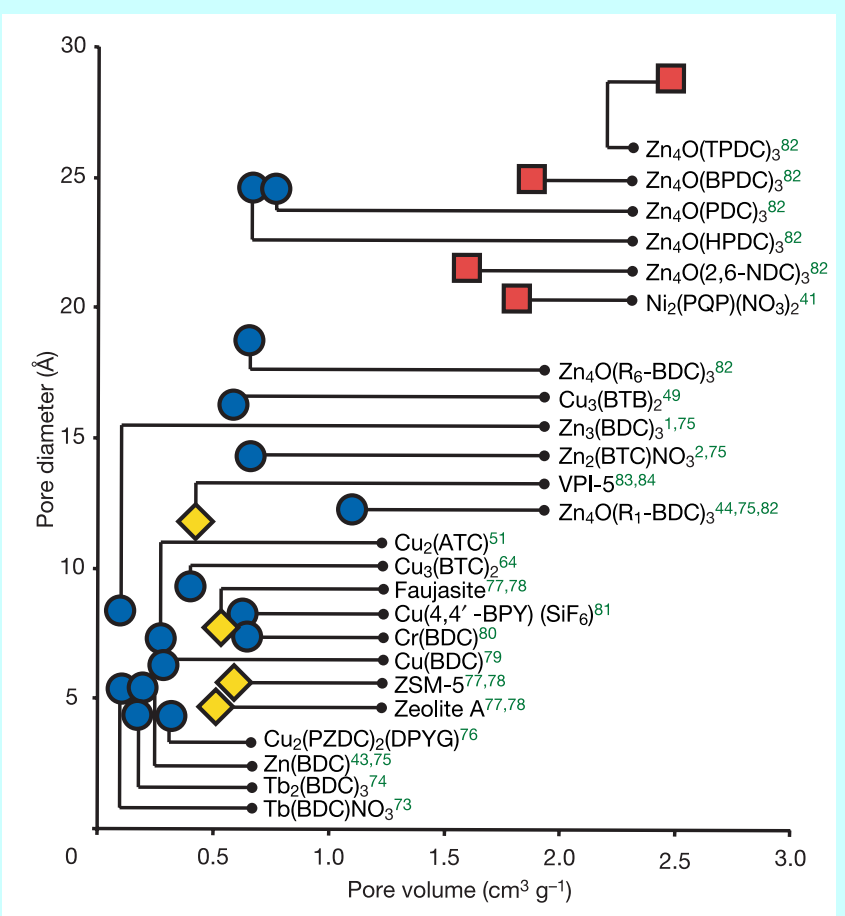

Figure 4 The porosity of MOFs compared to zeolites. Blue circles, sorption and crystal MOF structures; red squares, crystal MOF structures; yellow diamonds, some typical zeolites. Reference numbers (superscripted) are shown in green. diffraction studies ${ }^{82}$. The key element in synthesizing this series was to use the acid form of the link under reaction conditions known to form the octahedral SBU. In this series, the per cent free volume in crystals varies in small increments ( 1 to $5 \%$ ) starting from $55.8 \%$ $\left(\mathrm{R}_{5}\right.$-BDC) to an exceptional 91.1\% (TPDC).

It is worth noting that the lowest per cent free volume obtained in this series exceeds that found in some of the most open zeolites (Fig. 4) in which the free space is $45-50 \%$ of the crystal volume. In fact, the fraction of free space in crystals of the most expanded member (TPDC) of this series has only been achievable in non-crystalline porous systems such as $\mathrm{SiO}_{2}$ xerogels and aerogels ${ }^{87}$. Furthermore, the calculated crystal densities (in the absence of guests) of these materials also vary in small increments (around 0.1) in the range $1.00 \mathrm{~g} \mathrm{~cm}^{-3}$ ( $\mathrm{R}_{5}$-BDC) to $0.21 \mathrm{~g} \mathrm{~cm}^{-3}$ (TPDC) having densities, which are the lowest reported for any crystalline material. In comparison, the density of Li metal is $0.56 \mathrm{~g} \mathrm{~cm}^{-3}$. The ability to control and incrementally vary the metrics in this series has important technological implications. It has already been shown that the specific uptake of fuel gases such as methane in one member ( $\left.\mathrm{R}_{6}-\mathrm{BDC}\right)$ of the series is the highest known at present and comes close to meeting Department of Energy guidelines for use of natural gas in mobile applications.

In cognate work an isoreticular series based on lamellar $\mathrm{G}$ and $\mathrm{S}$ (guanidine-sulphonate) hydrogen-bonded materials has been achieved by varying the sulphonate functionality from DS-PGBDS (Box 1). Although these frameworks do not have permanent porosity as in MOFs, they provide advantages for selective crystallization-based separations ${ }^{88}$.

In addition to providing rigidity and structure information, SBUs can also impart physical properties to the framework. In the examples based on the paddle wheel and other binuclear clusters, the axial ligands are weakly bound to the porous framework, allowing their removal by heating or evacuation. The resulting open metal sites act as molecular imprints and site-isolated units $^{51}$, exhibiting highly selective binding of organic molecules and, in the case of $\mathrm{Tb}$ (III), luminescent behaviour that has formed a basis for sensing small molecules ${ }^{74}$.

Although porosity is almost an inevitable outcome of the SBU approach, other MOFs that have not been examined for their porosity have shown other interesting properties. Acentric SBUs can be assembled into MOFs having nonlinear optical properties, as illustrated for PCA- $1^{89}$. Here, a triangular SBU is linked by PCA-1 to give a decorated honeycomb-type framework. Similar frameworks have been designed using paramagnetic metal ions to produce ferromagnetic MOFs: links such as OX and OXM serve as magnetic coupling bridges in 2D ferromagnetic frameworks ${ }^{90,91}$. Recently, 3D magnetic frameworks have also been targeted using $\mathrm{Mn}$ (II), $\mathrm{Fe}$ (II), $\mathrm{Co}(\mathrm{II}), \mathrm{Ni}(\mathrm{II}), \mathrm{Cu}(\mathrm{II})$ and $\mathrm{Cr}(\mathrm{III})$ metal ions and $\mathrm{CN}^{92}, \mathrm{C}(\mathrm{CN})_{3}{ }^{93}$ and $\mathrm{Re}_{6} \mathrm{~S}_{8}(\mathrm{CN})_{6}{ }^{94}$ links to produce rutile and Prussian-blue type solids. A mixed-valence conductive framework based on BDC has been constructed from $\mathrm{V}(\mathrm{III} / \mathrm{IV})^{80}$, in which infinite vanadium oxide SBUs lead to the same $\mathrm{SrAl}_{2}$ topology found for MOF-6995.

\section{Logic of synthesis by design}

On the conceptual level, the underlying process for logical synthesis of MOFs starts with the designer choosing a specific target network, which is then deconstructed into its component geometric units. Molecular building blocks with the same geometry as those of the units are then assembled into a MOF structure that has the target network topology. The value of this approach is not limited to its utility in accessing a vast number of materials with predetermined structures: it also allows the designer to develop a deconstruction strategy for a target network. Such a deconstruction strategy becomes indispensable when designing non-default networks. This aspect is also addressed by reticular synthesis as shown in Fig. 5 for two basic networks; diamond and lonsdaleite ('hexagonal diamond') ${ }^{54,60}$. 
The designer of a material having these topologies would recognize that the simplest deconstruction scheme yields tetrahedral building blocks in both cases. Thus the assembly of molecules with tetrahedral shape would be expected to yield at least one of these two possible arrangements. However, in practice most structures (discussed above) obtained from simple tetrahedral building blocks are based on the cubic diamond network (Fig. 5a), which corresponds to the simplest, highest-symmetry structure (it is the only regular tetrahedral net) and unless the molecular building blocks contain information to the contrary, it is the default reticulation. Reticulations based on the lonsdaleite topology are rare.

We therefore investigated how reticular synthesis could be used to access non-default structures such as lonsdaleite. It is necessary to deconstruct its structure into more elaborate units that express structural features unique to its structure. Although the two structures are composed of fused six-membered rings, all such rings in diamond have the 'chair' conformation, whereas those in the hexagonal form assume both chair and 'boat' conformations as illustrated in Fig. 5. Thus it seems reasonable that to make frameworks based on lonsdaleite, the network should be deconstructed into units of fused chair and boat rings rather than of individual tetrahedra. In this way, the assembly of the corresponding molecular building blocks would yield exclusively the target network. We note that the above discussion does not preclude the possibility of achieving lonsdaleite from smaller units, if the structure formation were driven by the templating effect of included guest molecules ${ }^{96}$ as described in the next section.

This treatment can be universally applied to the design of crystalline molecular arrays of any dimensionality. We emphasize that the achievement of complex low-symmetry topologies by design requires the construction of complex molecular building blocks coded specifically for those topologies.

a

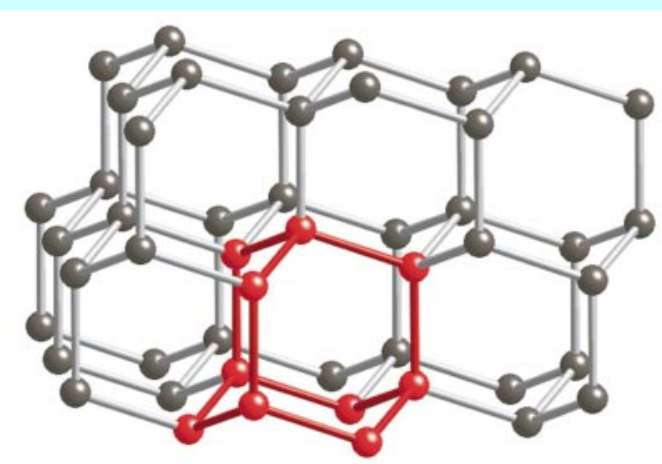

b

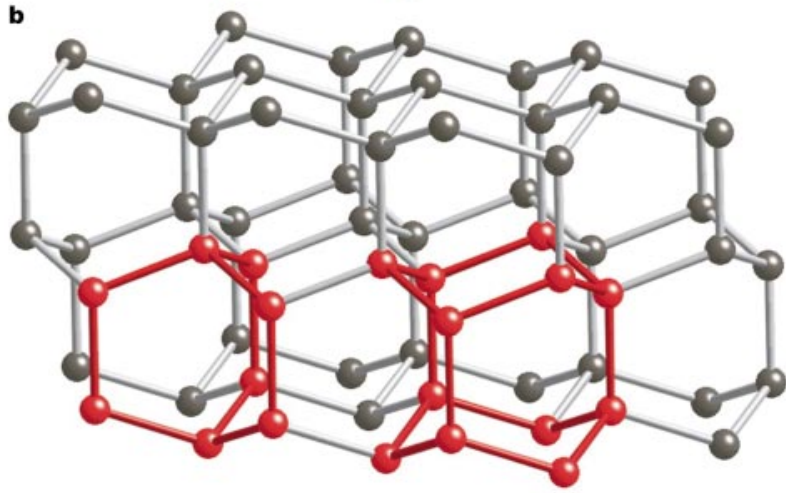

Figure $\mathbf{5}$ The deconstruction of diamond and lonsdaleite. $\mathbf{a}$, diamond; $\mathbf{b}$, lonsdaleite ('hexagonal diamond'). The units outlined in red are the natural tiles for these structures.

\section{Complexity and non-default structures}

The discussion so far has been limited to the design of frameworks in which the geometry of the links and/or vertices largely determines the outcome. In the formation of neutral frameworks, such as those of metal carboxylates, the role of the solvent in default structures is largely a space-filling one, although their function as structuredirecting agents (templates) becomes more important in the design of networks where the building blocks have more than one possible default structure ${ }^{96}$.

In particular, assembly of charged frameworks with counter ions requires careful matching of the charge, size and volume of counter ion to the charge per unit area of the target framework. This was illustrated in the assembly of T3 and T4 indium sulphide supertetrahedra, whose tetrahedral symmetry leads not only to the default diamond-like frameworks ${ }^{97}$, but also to the slightly less symmetric structures such as that of sodalite and the boron network in $\mathrm{CrB}_{4}{ }^{98}$. Here it is important to consider both the size and volume of the organic ammonium cations and the charge they provide per unit area of the prospective charged framework. We expect that similar factors must be considered to explain the formation of sodalite, feldspar and quartz MOF networks from tetrahedral $\mathrm{Cu}(\mathrm{I})$ and $\mathrm{HPMO}^{99}, \mathrm{PRM}^{100}$ and $2,2^{\prime}$-bpy $^{39}$, respectively. This analysis indicates that for some target non-default networks, elaborate units similar to those suggested for the reticular synthesis of lonsdaleite may not be the only option for their design.

\section{Future prospects}

Even with only the structures that are based on default networks, the immense wealth and scope of reticular chemistry has become apparent. In particular, design of the structural skeleton coupled with the ability to control its chemical functionalization and adjustment of its metric dimensions present exciting prospects. We have described here a conceptual approach to this subject, which we believe has proved useful, and which will continue to guide the designer.

Specific future challenges include the ability to design sophisticated molecular building blocks that would act as carriers of structural and functional information to be expressed in a specific target material. This will be of great benefit to many emerging technologies involving molecular electronics, miniature fuel cells, chiral catalysis and materials with hybrid properties.

doi:10.1038/nature01650.

Stein, A., Keller, S. W. \& Mallouk, T. E. Turning down the heat: Design and mechanism in solid-state synthesis. Science 259, 1558-1563 (1993).

2. Yaghi, O. M., O'Keeffe, M. \& Kanatzidis, M. G. Design of solids from molecular building blocks: golden opportunities for solid state chemistry. J. Solid State Chem. 152, 1-2 (2000).

3. Yaghi, O. M., Li, H., Davis, C., Richardson, D. \& Groy, T. L. Synthetic strategies, structure patterns, and emerging properties in the chemistry of modular porous solids. Acc. Chem. Res. 31, 474-484 (1998).

4. Batten, S. T. \& Robson, R. Interpenetrating nets: Ordered, periodic entanglement. Angew. Chem. Int. Edn Engl. 37, 1460-1494 (1998)

5. Férey, G. Building units design and scale chemistry. J. Solid State Chem. 152, 37-48 (2000).

6. Kitagawa, S. \& Kondo, M. Functional micropore chemistry of crystalline metal complex-assembled compounds. Bull. Chem. Soc. Jpn 71, 1739-1753 (1998).

7. Yaghi, O. M., O'Keeffe, M. \& Kanatzidis, M. G. Special issue on the design of solids from molecular building blocks: golden opportunities for solid state chemistry. J. Solid State Chem. 152, 1-321 (2000).

8. Eddaoudi, M. et al. Modular chemistry: Secondary building units as a basis for the design of highly porous and robust metal-organic carboxylate frameworks. Acc. Chem. Res. 34, 319-330 (2001).

9. Yaghi, O. M., Sun, Z., Richardson, D. A. \& Groy, T. L. Directed transformation of molecules to solids: Synthesis of microporous sulfide from molecular germanium sulfide cages. J. Am. Chem. Soc. 116, 807-808 (1994).

10. Corey, E. J. Retrosynthetic thinking-essentials and examples. Chem. Soc. Rev. 17, 111-133 (1988).

1. Lehn, J. M. Supramolecular chemistry-scope and perspectives. Chem. Scr. 28, 237-262 (1988).

12. Discussion 1: Innovation in Crystal Engineering CrystEngComm [online]; available at 〈http:// www.rsc.org/is/journals/current/crystengcomm/ceced.htm $\rangle$ (August 2002).

13. Moulton, B. \& Zaworotko, M. J. From molecules to crystal engineering: Supramolecular isomerism and polymorphism in network solids. Chem. Rev. 101, 1629-1658 (2001).

14. Braga, D., Grepioni, F. \& Desiraju, G. R. Crystal engineering and organometallic architecture. Chem. Rev. 98, 1375-1406 (1998).

15. Wells, A. F. Structural Inorganic Chemistry, (Oxford University Press, New York, 1984). 
16. Dunbar, K. R. \& Heintz, R. A. Chemistry of transition metal cyanide compounds: Modern perspectives. Prog. Inorg. Chem. 45, 283-391 (1997).

17. Gramaccioli, C. M. Crystal structure of zinc glutamate dihydrate. Acta Crystallogr. 21, 600-605 (1966).

18. Okada, K., Kay, M. I., Cromer, D. T. \& Almodovar, I. Crystal structure by neutron diffraction and antiferroelectric phase transition in copper formate tetrahydrate. J. Chem. Phys. 44, 1648-1653 (1966).

19. Jarvis, J. A. J. Crystal structure of a complex of cupric chloride and 1, 2, 4-triazole. Acta. Crystallogr 15, 964-966 (1962).

20. Sterling, C. Crystal structure of wedellite. Science 146, 518-519 (1964).

21. Robl, C. Water clustering in the zeolite-like channel structure of $\mathrm{Na}_{2} \mathrm{Zn}\left(\mathrm{C}_{6} \mathrm{H}_{2}(\mathrm{COO})_{4} \cdot 9 \mathrm{H}_{2} \mathrm{O}\right.$. Mater Res. Bull. 27, 99-107 (1992).

22. Weiss, A., Riegler, E., Alt, I., Bohme, H. \& Robl, C. Transition metal squarates 1. Chain structures $\mathrm{M}\left(\mathrm{C}_{4} \mathrm{O}_{4}\right) \cdot 4 \mathrm{H}_{2} \mathrm{O}$. Z. Naturforsch. B. 41, 18-24 (1986).

23. Kinoshita, Y., Matsubara, I., Higuchi, T. \& Saito, Y. The crystal structure of bis (adiponitrilo)copper(I) nitrate. Bull. Chem. Soc. Jpn 32, 1221-1226 (1959).

24. Aumüller, A. et al. A radical anion salt of 2, 5-dimethyl-N, $\mathrm{N}^{\prime}$-dicyanoquinonediimine with extremely high electrical conductivity. Angew. Chem. Int. Edn Engl. 25, 740-741 (1986).

25. Hoskins, B. F. \& Robson, R. Infinite polymeric frameworks consisting of three dimensionally linked rod-like segments. J. Am. Chem. Soc. 111, 5962-5964 (1989).

26. Kim, J. et al. Assembly of metal-organic frameworks from large organic and inorganic secondary building units: new examples and simplifying principles for complex structures. J. Am. Chem. Soc. 123, 8239-8247 (2001)

27. Brimah, A. K. et al. Towards organometallic zeolites: spontaneous self-assembly of $\mathrm{Et}_{3} \mathrm{SnCN}, \mathrm{CuCN}$ and $\left({ }^{\mathrm{n}} \mathrm{Bu}_{4} \mathrm{~N}\right) \mathrm{CN}$ to supramolecular $\left[\left({ }^{\mathrm{n}} \mathrm{Bu}_{4} \mathrm{~N}\right)\left(\mathrm{Et}_{3} \mathrm{Sn}\right)_{2} \mathrm{Cu}(\mathrm{CN})_{4}\right]$. J. Organometall. Chem. 475, 85-94 (1994)

28. Evans, O. R., Wang, Z. Y., Xiong, R. G., Foxman, B. M. \& Lin, W. B. Nanoporous interpenetrated metal-organic diamondoid networks. Inorg. Chem. 38, 2969-2973 (1999).

29. Yaghi, O. M., Richardson, D. A., Li, G., Davis, C. E. \& Groy, T. L. Open-framework solids with diamond-like structures prepared from clusters and metal-organic building blocks. Mater. Res. Soc Symp. Proc. 371, 15-19 (1995).

30. MacGillivray, L. R., Subramanian, S. \& Zaworotko, M. J. Interwoven two- and three-dimensional coordination polymers through self-assembly of $\mathrm{Cu}$ (I) cations with linear bidentate ligands. Chem Commun., 1325-1326 (1994).

31. Hirsch, K. A., Venkataraman, D., Wilson, S. R., Moore, J. S. \& Lee, S. Crystallization of 4, 4' biphenyldicarbonitrile with silver (I) salts- a change in topology concomitant with change in counterion leading to a nine diamond network. Chem. Commun., 2199-2200 (1995).

32. Carlucci, L. et al. Self-assembly of a three-dimensional network from two dimensional layers via metallic spacers: the $(3,4)$-connected frame of $\left[\mathrm{Ag}_{3}(\mathrm{hmt})_{2}\right]\left[\mathrm{ClO}_{4}\right]_{3} \cdot 2 \mathrm{H}_{2} \mathrm{O}$ (hmt $=$ hexamethylenetetramine). Chem. Commun., 631-632 (1997).

33. Klein, C., Graf, E., Hosseini, M. W. \& De Cian, A. Design and structural analysis of interpenetrated 3-D coordination networks formed from self-assembly using tetrapyridinocyclophane and silver cations. New J. Chem. 25, 207-209 (2001).

34. Simard, M., Su, D. \& Wuest, J. D. Use of hydrogen bonds to control molecular aggregation. Self-assembly of three-dimensional networks with large chambers. J. Am. Chem. Soc. 113, 4696-4698 (1991).

35. Ermer, O. Fivefold-diamond structure of adamantane-1,3,5,7-tetracarboxylic acid. J. Am. Chem. Soc $110,3747-3754(1988)$

36. Blake, A. J., Champness, N. R., Hubbertstey, P., Li, W., Withersby, M. A. \& Schroder, M. Inorganic crystal engineering using self-assembly of tailored building-blocks. Coord. Chem. Rev. 183, 117-138 (1999).

37. Carlucci, L., Ciani, G., Macchi, P. \& Proserpio, D. M. An unprecedented triply interpenetrated chiral network of 'square planar' metal centres from the self assembly of copper(II) nitrate and 1,2-bis(4-pyridyl)ethyne. Chem. Commun., 1837-1838 (1998).

38. Carlucci, L., Ciani, G., Proserpio, D. M. \& Rizzato, S. New examples of self-catenation in three dimensional co-ordination networks. J. Chem. Soc. Dalton Trans., 3821-3827 (2000).

39. Carlucci, L., Ciani, G., Proserpio, D. M. \& Rizzato, S. Interlinked molecular squares with $\left[\mathrm{Cu}\left(2,2^{\prime}\right.\right.$ bipy) $]^{2+}$ corners generating a three-dimensional network of unprecedented topological type. Chem Commun., 1198-1199 (2001).

40. Evans, O. R. \& Lin, W. Crystal engineering in NLO materials based on metal-organic coordination networks. Acc. Chem. Res. 35, 511-522 (2002)

41. Biradha, K., Hongo, Y. \& Fujita, M. Open square-grid coordination polymers of the dimension $20 \times 20 \AA$ : remarkably stable and crystalline solids even after guest removal. Angew. Chem. Int. Edn Engl. 39, 3843-3845 (2000)

42. Yaghi, O. M., Li, H. \& Groy, T. L. A molecular railroad with large pores: synthesis and structure of $\mathrm{Ni}\left(4,4^{\prime} \text {-bpy }\right)_{2.5}\left(\mathrm{H}_{2} \mathrm{O}\right)_{2}\left(\mathrm{ClO}_{4}\right) \cdot 1.5\left(4,4^{\prime}\right.$-bpy $) \cdot 2 \mathrm{H}_{2} \mathrm{O}$. Inorg. Chem. 36, 4292-4293 (1997).

43. Li, H., Eddaoudi, M., Groy, T. L. \& Yaghi, O. M. Establishing microporosity in open metal-organi frameworks: gas sorption isotherms for $\mathrm{Zn}(\mathrm{BDC})$ ( $\mathrm{BDC}=1,4$-benzenedicarboxylate). J. Am. Chem. Soc. 120, 8571-8572 (1998)

44. Li, H., Eddaoudi, M., O'Keeffe, M. \& Yaghi, O. M. Design and synthesis of an exceptionally stable and highly porous metal-organic framework. Nature 402, 276-279 (1999).

45. Yaghi, O. M., Davis, C. E., Li, G. \& Li, H. Selective guest binding by tailored channels in a 3-D porous zinc(II) benzenetricarboxylate network. J. Am. Chem. Soc. 119, 2861-2868 (1997).

46. Barthelet, K., Riou, D. \& Ferey, G. $\left[\mathrm{V}^{\mathrm{III}}\left(\mathrm{H}_{2} \mathrm{O}\right)\right]_{3} \mathrm{O}\left(\mathrm{O}_{2} \mathrm{CC}_{6} \mathrm{H}_{4} \mathrm{CO}_{2}\right)_{3} \cdot\left(\mathrm{Cl}, 9 \mathrm{H}_{2} \mathrm{O}\right)$ (MIL-59): A rare example of vanadocarboxylate with a magnetically frustrated three-dimensional hybrid framework. Chem. Commun., 1492-1493 (2002).

47. Yang, S. Y., Long, L. S., Jiang, Y. B., Huang, R. B. \& Zheng, L. S. An exceptionally stable metal-organic framework constructed from the $\mathrm{Zn}_{8}\left(\mathrm{SiO}_{4}\right)$ core. Chem. Mater. 14, 3229-3231 (2002).

48. Eddaoudi, M. et al. Geometric requirements and examples of important structures in the assembly of square building blocks. Proc. Natl. Acad. Sci. USA 99, 4900-4904 (2002)

49. Chen, B., Eddaoudi, M., Hyde, S. T., O’Keeffe, M. \& Yaghi, O. M. Interwoven metal-organic framework on a periodic minimal surface with extra-large pores. Science 291, 1021-1023 (2001)

50. Diskin-Posner, Y., Dahal, S. \& Goldberg, I. Crystal engineering of metalloporphyrin zeolite analogues. Angew. Chem. Int. Edn Engl. 39, 1288-1292 (2000).
51. Chen, B. et al. $\mathrm{Cu}_{2}(\mathrm{ATC}) \cdot 6 \mathrm{H}_{2} \mathrm{O}$ : Design of open metal sites in porous metal-organic crystals (ATC: 1,3,5,7-adamantane tetracarboxylate). J. Am. Chem. Soc. 122, 11559-11560 (2000).

52. Chae, H. K. et al. Tertiary building units: Synthesis, structure, and porosity of a metal-organic dendrimer framework (MODF-1). J. Am. Chem. Soc. 123, 11482-11483 (2001).

53. O’Keeffe, M. \& Brese, N. E. Uninodal 4-connected nets I: Nets without 3- or 4-rings. Act Crystallogr. A 48, 663-669 (1992).

54. O'Keeffe, M., Eddaoudi, M., Li, H., Reineke, T. \& Yaghi, O. M. Frameworks for extended solids: geometrical design principles. J. Solid State Chem. 152, 3-20 (2000).

55. Delgado Friedrichs, O., Dress, A. W. M., Huson, D. H., Klinowski, J. \& Mackay, A. L. Systematic enumeration of crystalline networks. Nature 400, 644-647 (1999).

56. O’Keeffe, M. Tiling by numbers. Nature 400, 617-618 (1999).

57. Delgado Friedrichs, O. \& Huson, D. H. 4-regular vertex-transitive tilings of $\mathrm{E}^{3}$. Discr. Comput. Geom. 24, 279-292 (2000)

58. Fischer, W. \& Koch, E. in International Tables For Crystallography A (ed. Hahn, Th.) Ch. 14 (Kluwer, Dordrecht, 1983).

59. Delgado Friedrichs, O., O'Keeffe, M. \& Yaghi, O. M. Three-periodic nets and tilings: regular and quasiregular nets. Acta Crystallogr. A 59, 22-27 (2003).

60. O'Keeffe, M. \& Hyde, B. G. Crystal structures, I. Patterns and symmetry (Mineralogical Society of America, Washington, DC, 1996)

61. Eddaoudi, M. et al. Porous metal-organic polyhedra: 25 angstrom cuboctahedron constructed from $12 \mathrm{Cu}_{2}\left(\mathrm{CO}_{2}\right)_{4}$ paddle wheel building blocks. J. Am. Chem. Soc. 123, 4368-4369 (2001)

62. Moulton, B., Lu, J., Mondal, A. \& Zaworotko, M. Z. Nanoballs: nanoscale faceted polyhedra with large windows and cavities. Chem. Commun., 863-864 (2001).

63. Eddaoudi, M., Kim, J., O'Keeffe, M. \& Yaghi, O. M. $\mathrm{Cu}_{2}\left[o-\mathrm{Br}_{-} \mathrm{C}_{6} \mathrm{H}_{3}\left(\mathrm{CO}_{2}\right)_{2}\right]_{2}\left(\mathrm{H}_{2} \mathrm{O}\right)_{2} \cdot(\mathrm{DMF})_{8}\left(\mathrm{H}_{2} \mathrm{O}\right)_{2}$ : A framework deliberately designed to have the $\mathrm{NbO}$ structure type. J. Am. Chem. Soc. 124, 376-377 (2002).

64. Chu, S. S. Y., Lo, S. M. F., Charmant, J. P. H., Orpen, A. G. \& Williams, I. D. A chemically functionalizable nanoporous material $\mathrm{Cu}_{3}(\mathrm{TMA})_{2}\left(\mathrm{H}_{2} \mathrm{O}\right)_{3}$. Science 283, 1148-1150 (1999).

65. Kepert, C. J., Prior, T. J. \& Rosseinsky, M. J. A versatile family of interconvertible microporous chiral molecular frameworks: the first example of ligand control of network chirality. J. Am. Chem. Soc. 122, 5158-5168 (2000).

66. Seo, J. S. et al. A homochiral metal-organic porous material for enantioselective separation and catalysis. Nature 404, 982-986 (2000)

67. Fujita, M. et al. On the structure of transition-metal-linked molecular squares. Chem. Commun., 1535-1536 (1996).

68. Stang, P. T. \& Olenyuk, B. Self-assembly, symmetry, and molecular architecture: coordination as the motif in the rational design of supramolecular metallacyclic polygons and polyhedra. Acc. Chem. Res. 30, 502-518 (1997).

69. MacGillivray, L. R. \& Atwood, J. L. A chiral spherical molecular assembly held together by 60 hydrogen bonds. Nature 389, 469-472 (1997).

70. Caulder, D. L. \& Raymond, K. N. Supermolecules by design. Acc. Chem. Res. 32, 975-982 (1999).

71. Cotton, F. A., Lin, C. \& Murillo, C. A. Supramolecular arrays based on dimetal building units. Acc. Chem. Res. 34, 759-771 (2001).

72. Gregg, S. J. \& Sing, K. S. W. Adsorption, Surface Area and Porosity (Academic Press, New York, 1982)

73. Reineke, T. M., Eddaoudi, M., O’Keeffe, M. \& Yaghi, O. M. A microporous lanthanide-organic framework. Angew. Chem. Int. Edn Engl. 38, 2590-2594 (1999).

74. Reineke, T., Eddaoudi, M., Fehr, M., Kelley, D. \& Yaghi, O. M. From condensed lanthanide coordination solids to microporous frameworks having accessible metal sites. J. Am. Chem. Soc. 121, 1651-1657 (1999)

75. Eddaoudi, M., Li, H. \& Yaghi, O. M. Highly porous and stable metal-organic frameworks: Structure design and sorption properties. J. Am. Chem. Soc. 122, 1391-1397 (2000)

76. Kitaura, R., Fujimoto, K., Noro, S., Kondo, M. \& Kitagawa, S. A pillared-layer coordination polymer network displaying hysteretic sorption: $\left[\mathrm{Cu}_{2}(\mathrm{pzdc})_{2}(\mathrm{dpyg})\right]_{\mathrm{n}}(\mathrm{pzdc}=$ pyrazine-2,3-dicarboxylate dpyg = 1,2-Di(4-pyridyl)-glycol). Angew. Chem. Int. Edn Engl. 41, 133-135 (2002).

77. Szostak, R. Molecular Sieves: Principles of Synthesis and Identification (Van Nostrand Reinhold, New York, 1989).

78. Bhatia, S. Zeolite Catalysis: Principles and Applications (CRC Press, Boca Raton, Florida, 1990).

79. Seki, K., Takamizawa, S. \& Mori, W. Design and gas adsorption property of a three-dimensional coordination polymer with a stable and highly porous framework. Chem. Lett., 332-333 (2001).

80. Millange, F., Serre, C. \& Férey, G. Synthesis, structure determination and properties of MIL-53as and MIL-53ht: the first $\mathrm{Cr}^{\mathrm{III}}$ hybrid inorganic-organic microporous solids: $\mathrm{Cr}^{\mathrm{III}}(\mathrm{OH}) \cdot\left\{\mathrm{O}_{2} \mathrm{C}-\mathrm{C}_{6} \mathrm{H}_{4^{-}}\right.$ $\left.\mathrm{CO}_{2}\right\} \cdot\left\{\mathrm{HO}_{2}-\mathrm{C}_{6} \mathrm{H}_{4}-\mathrm{CO}_{2} \mathrm{H}\right\}$. Chem. Commun., 822-823 (2002).

81. Noro, S., Kitagawa, S., Kondo, M. \& Seki, M. A new methane adsorbent, porous coordination polymer $\left[\left\{\mathrm{CuSiF}_{6}\left(4,4^{\prime} \text {-bipyridine }\right)_{2}\right\}_{\mathrm{n}}\right]$. Angew. Chem. Int. Edn Engl. 39, 2082-2084 (2000).

82. Eddaoudi, M. et al. Systematic design of pore size and functionality in isoreticular MOFs and their application in methane storage. Science 295, 469-472 (2002).

83. Davis, M. E., Montes, C., Hathaway, P. E., Arhancet, J. P., Hasha, D. L. \& Garces, J. M. Physicochemical properties of VPI-5. J. Am. Chem. Soc. 111, 3919-3924 (1989).

84. Davis, M. E. Ordered porous materials for emerging applications. Nature 417, 813-821 (2002).

85. O’Keeffe, M. \& Stuart, J. A. Bond energies in solid oxides. Inorg. Chem. 22, 177-179 (1983).

86. Kiang, Y. H., Gardner, G. B., Lee, S., Xu, Z. \& Lobkovsky, E. B. Variable pore size, variable chemical functionality, and an example of reactivity within porous phenylacetylene silver salts. J. Am. Chem. Soc. 121, 8204-8215 (1999).

87. Husing, N. \& Schubert, U. Aerogels airy materials: Chemistry, structure, and properties. Angew. Chem. Int. Edn Engl. 37, 23-45 (1998).

88. Holman, K. T., Pivovar, A. M., Swift, J. A. \& Ward, M. D. Metric engineering of soft molecular host frameworks. Acc. Chem. Res. 34, 107-118 (2001).

89. Lin, W. B., Wang, Z. \& Ma, L. A novel octupolar metal-organic NLO material based on chiral 2Dcoordination network. J. Am. Chem. Soc. 121, 11249-11250 (1999).

90. Farrell, R. P., Hambley, T. W. \& Lay, P. A. A new class of layered microporous materials: crysta structure of disodium pentakis(trimethylphenylammonium) bis[tris(oxalato(2))-chromate(III)] chloride pentahydrate. Inorg. Chem. 34, 757-758 (1995)

91. Kahn, O. Chemistry and physics of supramolecular magnetic materials. Acc. Chem. Res. 33, 647-657 (2000). 
92. Sato, O., Iyoda, T., Fujishima, A. \& Hashimoto, K. Electochemically tunable magnetic phase transition in a high- $T_{c}$ chromium cyanide thin film. Science 271, 49-51 (1996).

93. Manson, J. L., Campana, C. \& Miller, J. S. Interpenetrating three-dimensional rutile-like frameworks Crystal structure and magnetic properties $\mathrm{Mn}^{\mathrm{II}}\left[\mathrm{C}(\mathrm{CN})_{3}\right]_{2}$. Chem. Commun., 251-252 (1998).

94. Bennett, M. V., Beauvais, L. G., Shores, M. P. \& Long, J. R. Expanded prussian blue analogue incorporating $\left[\mathrm{Re}_{6} \mathrm{Se}_{8}(\mathrm{CN})_{6}\right]^{3-/ 4-}$ clusters: adjusting porosity via charge balance. J. Am. Chem. Soc 123, 8022-8032 (2001).

95. Rosi, N. L. et al. Infinite secondary building units and forbidden catenation in metal-organic frameworks, N. L. Angew. Chem. Int. Edn Engl. 41, 284-287 (2001).

96. Kitazawa, T., Kikuyama, T., Takeda, M. \& Iwamoto, T. Silica-mimetic polymorphism of the $\mathrm{Cd}(\mathrm{CN})_{2}$ host lattice depending on the guest $\mathrm{G}$ in $\mathrm{Cd}(\mathrm{CN})_{2} \cdot x \mathrm{G}$ clathrates. J. Chem. Soc. Dalton Trans. 22 3715-3720 (1995).

97. Li, H., Eddaoudi, M., Laine, A., O'Keeffe, M. \& Yaghi, O. M. Noninterpenetrating indium sulfide supertetrahedral cristobalite framework. J. Am. Chem. Soc. 121, 6096-6097 (2001).
98. Li, H., Laine, A., O'Keeffe, M. \& Yaghi, O. M. Supertetrahedral sulfide crystals with giant cavities and channels. Science 283, 1145-1147 (1999).

99. Tabares, L. C., Navarro, J. A. R. \& Salas, J. M. Cooperative guest inclusion by a zeolite analogue coordination polymer: sorption behaviour with gases and amine and group 1 metal salts. J. Am. Chem. Soc. 123, 383-387 (2001).

100. Keller, S. W. An acentric, three dimensional coordination polymer: synthesis and structure of $\left.[\mathrm{Cu} \text { (pyrimidine) })_{2}\right] \mathrm{BF}_{4}$. Angew. Chem. Int. Edn Engl. 36, 247-248 (1997).

Acknowledgements O.M.Y. and M.O'K. thank the NSF and the DOE (O.M.Y.) for their support of research in their respective laboratories on the subject of this contribution.

Correspondence and requests for materials should be addressed to O.M.Y

(oyaghi@umich.edu). 